\title{
The Effect of Thymoquinone, $\alpha 7$ Receptor Agonist and $\alpha 7$ Receptor Allosteric Modulator on the Cerebral Cortex in Experimentally Induced Alzheimer's Disease in Relation to MSCs Activation
}

\author{
Lamiaa Ibrahim AbdEl Fattah ${ }^{1}$, Maha Baligh Zickri ${ }^{1}$, Lobna Abdel Aal ${ }^{1}$, Ola Heikal ${ }^{1}$, Esraa Osama ${ }^{2}$ \\ ${ }^{I}$ Department of Histology, Faculty of Medicine, Cairo University, \\ ${ }^{2}$ Department of Physiology and Toxicology, Faculty of Pharmacy E Biotechnology-German University in Cairo (GUC), Egypt
}

Background and Objectives: Alzheimer's disease (AD) is the most common form of dementia among older persons. Thymoquinone (TQ) has anti-inflammatory, anticonvulsant and antioxidant activity. A novel $\alpha 7$ nicotinic acetyl choline receptor ( $\alpha 7 \mathrm{nAChR}$ ) agonist (PNU- 282987) have been identified to enhance the cognitive performance. An alternative treatment strategy via compounds known as nicotinic "positive allosteric modulators" (PAMs) has been reported. This study was designed to investigate the combination of PAM of $\alpha 7$ nAChRs with PNU- 282987 or with $\mathrm{TQ}$ as a possible treatment for $\mathrm{AD}$ in rat.

Methods: 48 male albino rats were divided into 4 groups. Group I (Control), Group II received lipopolysaccharide, $0.8 \mathrm{mg} / \mathrm{kg}$ by intraperitoneal injection (IPI) once, Group III received TQ $10 \mathrm{mg} / \mathrm{kg}$ by IPI, Group IV received PNU-120596 $1 \mathrm{mg} / \mathrm{kg}$ by IPI, in addition to PNU-282987 $1 \mathrm{mg} / \mathrm{kg}$ by IPI in subgroup IVa and TQ in subgroup b. All treatment drugs were given for 5 days.

Results: Acidophilic masses, deformed neurons, Congo red + ve masses and reduced Phospho-CREB immunoexpression were seen in group II. All changes regressed by treatment. Some CD44 + ve cells were noticed in group II and few +ve cells in subgroup IVa, that became multiple in group III and subgroup IVb. The histological, histochemical and immunohistochemical changes were confirmed statistically and significant differences were recorded.

Conclusions: TQ or $\alpha 7 \mathrm{nAChR}$ agonist combined with PAM can have an important role in treatment of $\mathrm{AD}$ that is superior to thymoquinone alone. Exceptionally, TQ single or combined with PAM proved activation of MSC.

Keywords: Alzheimer's disease, LPS, Thymoquinone, PNU- 282987, PNU- 120596, MSCs

Accepted for publication June 21, 2016, Published online November 30, 2016

Correspondence to Maha Baligh Zickri

Department of Histology, Faculty of Medicine, Cairo University, Egypt

Tel: $+2 / 0123955078$, Fax: $+0020235381183,+0020235381760$

E-mail:maha_kaah@yahoo.com

(c) This is an open-access article distributed under the terms of the Creative Commons Attribution Non-Commercial License (http://creativecommons.org/ licenses/by-nc/4.0/), which permits unrestricted non-commercial use, distribution, and reproduction in any medium, provided the original work is properly cited.

\section{Introduction}

Alzheimer's disease (AD) is the most common form of dementia among older persons. Pathognomonic hallmarks of the disease include the development of beta -amyloid $(\mathrm{A} \beta)$ senile plaques and deposits of neurofibrillary tangles. Thus, compounds that could interfere with $\mathrm{A} \beta$ formation may be potential therapeutic agents for treatment of $\mathrm{AD}(1)$.

Thymoquinone (TQ) is the main constituent of Nigella Sativa (black seed) oil with many pharmacological properties including anti-inflammatory, anticonvulsant, anti- 
tumour and antioxidant activity (2).

The primary therapeutic strategy for treating the cognitive dysfunction in $\mathrm{AD}$ has been cholinergic replacement strategy, based on researches which indicated that cholinergic neurons in the forebrain support information processing and cognition which become compromised with age especially in AD. Moreover, both nicotinic and muscarinic acetylcholine receptors are considered important therapeutic targets for improving cognition in $\mathrm{AD}$ (3).

A novel $\alpha 7$ nicotinic acetyl choline receptor ( $\alpha 7$ $\mathrm{nAChR}$ ) selective agonist have been identified to enhance the cognitive performance. PNU- 282987 has been shown to be a potent and most specific $\alpha 7 \mathrm{nAChR}$ agonist. Moreover, PNU had significant effects on memory thus improving performance (4).

An alternative treatment strategy via compounds known as nicotinic "positive allosteric modulators" (PAMs) has been reported. PAM of $\alpha 7 \mathrm{nAChRs}$ is known as PNU120596 (3).

The present study aimed at investigating the combination of PAM of $\alpha 7 \mathrm{nAChRs}$ with PNU- 282987 ( $\alpha 7$ nAChR agonist) OR with TQ as a possible treatment for $\mathrm{AD}$ in an animal model using histological, histochemical, immunohistochemical and morphometric methods.

\section{Materials and Methods}

\section{Drugs and chemicals}

Lipopolysaccharide (LPS) was obtained from (Sigma Aldrich, Germany) in the form of powder (1g vial) dissolved in phosphate buffered saline.

Thymoquinone (TQ) was obtained from (Sigma Aldrich, Germany) in the form of yellow crystals (1g vial) dissolved in tween 80.

PNU-282987 ( $\alpha 7$ nAChR agonist) was obtained from (Abcam Biochemicals, USA) in the form of powder (10 mg vial) dissolved in phosphate buffered saline.

PNU-120596 ( $\alpha 7$ allosteric modulator) was obtained from (Abcam Biochemicals, USA) in the form of powder (10 mg vial) dissolved in phosphate buffered saline.

\section{Animals}

Forty eight male albino rats aged 9 months weighing 200 250 g were used in the present study. The animals were housed in the Animal House of the German University in Cairo (GUC), under good hygienic conditions of air, temperature, fed ad libitum and allowed for free water supply. The animals were treated according to the ethical guidelines of GUC and Cairo University.

The animals were divided into four groups, kept in sep- arate cages as follows

Group 1 (Control Group): Included eight rats (each 2 were sacrificed with the rats of each experimental group and subgroup).

Two rats, each received $0.1 \mathrm{ml}$ PBS by intraperitoneal injection (IPI) once.

Two rats, each received $0.1 \mathrm{ml}$ PBS by IPI once then on the $3^{\text {rd }}$ day each received $0.3 \mathrm{ml}$ tween 80 by IPI for 5 days.

Two rats, each received $0.1 \mathrm{ml}$ PBS by IPI once then on the $3^{\text {rd }}$ day each received $0.1 \mathrm{ml}$ PBS by IPI for 5 days.

Two rats, each received $0.1 \mathrm{ml}$ PBS by IPI once then on the $3 \mathrm{rd}$ day each received $0.3 \mathrm{ml}$ tween 80 and $0.1 \mathrm{ml}$ PBS by IPI for 5 days.

The control rats were sacrificed 1 week from the start of the experiment.

Group 2 (LPS Group): Included ten rats, each received LPS $0.8 \mathrm{mg} / \mathrm{kg}$ dissolved in $0.1 \mathrm{ml}$ PBS by IPI once (5).

Group 3 (LPS and TQ Group): Included ten rats, each was given LPS in the same dose, by the same route and for the same duration as in group 2. On the $3^{\text {rd }}$ day TQ was given by IPI $(10 \mathrm{mg} / \mathrm{kg})$ dissolved in $0.3 \mathrm{ml}$ tween 80 (2) for 5 consecutive days for each rat.

Group 4 (LPS and PNU-120596 Group): Twenty rats, each received LPS in the same dose, by the same route and for the same duration as in group 2 . On the $3^{\text {rd }}$ day PNU-120596 was given by IPI (1 mg/kg) dissolved in 0.1 $\mathrm{ml}$ PBS (6) for 5 consecutive days for each rat.

The animals were further subdivided into 2 subgroups according to drug therapy:

Subgroup 4a: Ten rats, each given PNU-282987 in addition by IPI $(1 \mathrm{mg} / \mathrm{kg})$ dissolved in $0.1 \mathrm{ml}$ PBS for 5 consecutive days for each rat (7).

Subgroup 4b: Ten rats, each given TQ in addition as in group 3.

In all experimental groups and subgroups, the rats were sacrificed one week from the start of the experiment.

The rats belonging to experimental groups, subgroups and corresponding control rats were sacrificed by cervical dislocation (8) following ether anaesthesia. The skull was opened by bone cutter at the temporal regions. The brain was exposed and immediately dissected out, the frontal lobes were separated following placing in $10 \%$ formol saline for 48 hours at room temperature. Frontal lobe specimens were embedded into paraffin wax. Coronal sections of $5 \mu \mathrm{m}$ thickness were prepared and subjected to the following studies:

Histological Study: Hematoxylin and eosin (9)

Histochemical study: Congo Red staining to demonstrate the amyloid plaques (10). 


\section{Immunohistochemical Study:}

1. Anti-phospho-cyclic adenosine phosphate (cAMP) response element binding protein (P-CREB) (11) immunostaining, a beta transcription factor that activates target genes through cAMP response elements, CREB plays a key role in neuronal survival, precursor proliferation and neuronal differentiation. Primary antibody (Ab) rabbit polyclonal supplier (Merck Milipore, Germany) catalog number (06-519) used as $0.1 \mathrm{ml}$ diluted stored at $2 \sim 8^{\circ} \mathrm{C}$.

2. CD44 Ab to detect the endogenous MSCs (12). $7 \mathrm{ml}$ prediluted rabbit monoclonal 1ry Ab (IW-PA1021) (IHC World, Ellicott City, USA) stored at $2 \sim 8^{\circ} \mathrm{C}$.

The primary $\mathrm{Ab}$ was applied to the sections for $60 \mathrm{mi}-$ nutes at RT for both markers. The + ve tissue control was a specimen of brain tissue for P-CREB and a specimen of human tonsil for CD44. P-CREB + ve cells showed nuclear reaction while CD44 +ve cells showed membranous reaction. The -ve tissue control was processed in the same way, but omitting the step of 1ry Ab.

\section{Morphometric Study}

Using Leica Qwin 500 LTD (Cambridge UK) computer assisted image analyzer. The area of deformed neurons, glial cells and that of amyloid plaques were measured. The measurements were done in 10 high power fields (HPF) using interactive measurements menu. Area \% of P-CREB +ve nuclei and CD44 +ve cells were measured. The measurements were done in $10 \mathrm{HPF}$ using binary mode.

\section{Statistical analysis}

Quantitative data were summarized as means and standard deviations (SD) and compared using one-way analysis-of-variance (ANOVA). p-values $<0.05$ were considered statistically significant. Calculations were made on social package of statistical study software version 16 (13).

\section{Results}

None of the animals died during the experiment. Moreover, gross examination of the brains from all rats at the end of the experiment showed no apparent lesions.
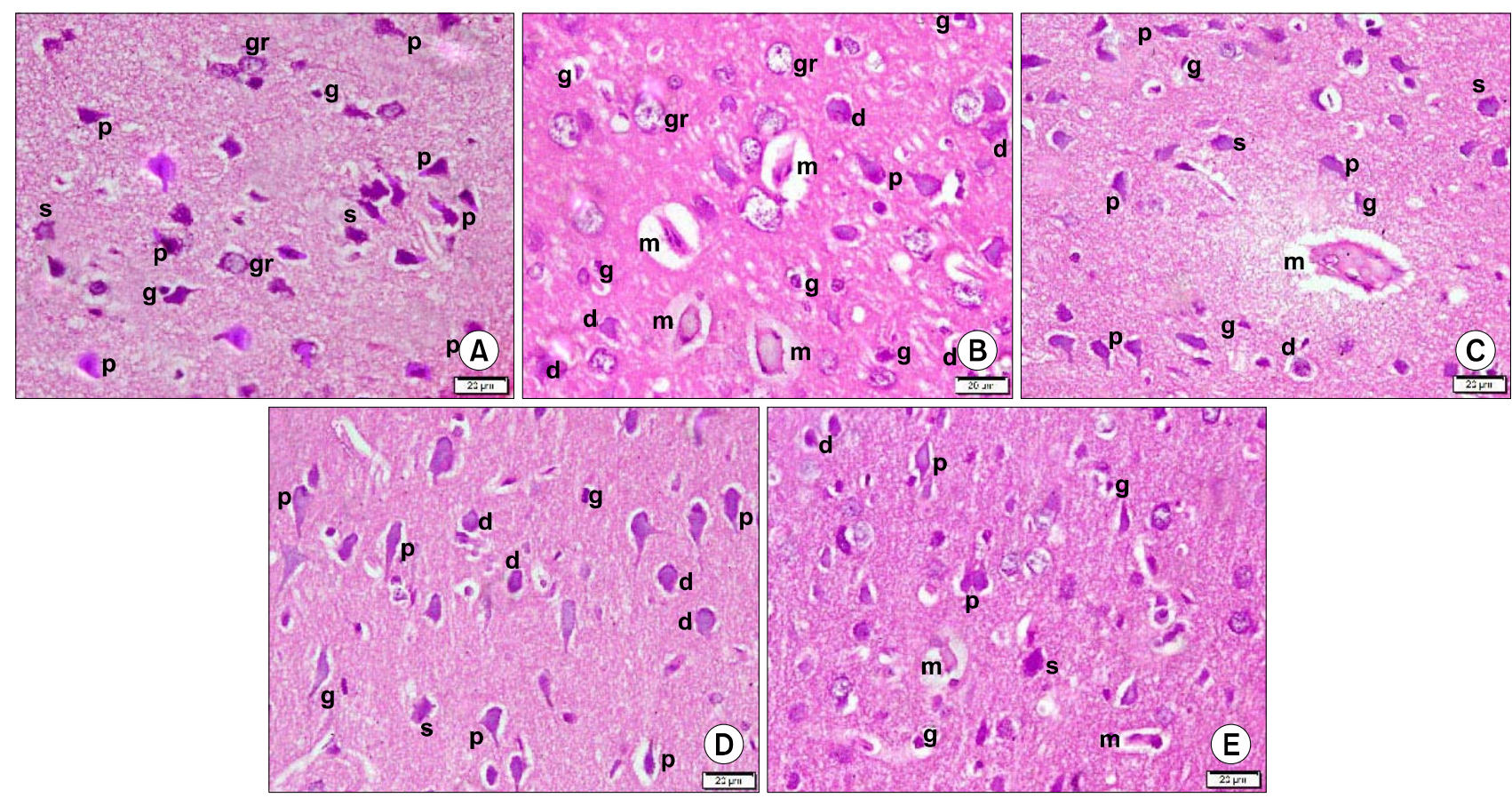

Fig. 1. Photomicrographs of sections in the frontal area of cerebral cortex (EPL) (H\&E, x400). (A) of a rat in group 1 showing multiple pyramidal (p), few stellate (s) and few granule (gr) neurons. Note few glial cells (g) in neuropil. (B) of a rat in group 2 showing 4 acidophilic masses $(m)$ exhibiting dark nuclei and surrounded by a clear space. Multiple deformed (d), few pyramidal (p) and granule (gr) neurons are seen. Note multiple glial cells (g). (C) of a rat in group 3 showing an acidophilic mass $(\mathrm{m})$ exhibiting dark nuclei and surrounded by a clear space. Few deformed (d), some pyramidal (p) and few stellate (s) neurons are seen. Note some glial cells (g). (D) of a rat in subgroup 4a showing few deformed (d), multiple pyramidal $(\mathrm{p})$ and few stellate (s) neurons. Note few glial cells (g). (E) of a rat in subgroup 4b showing 2 small acidophilic masses $(\mathrm{m})$ exhibiting dark nuclei and surrounded by a clear space. Few deformed (d), multiple pyramidal (p) and few stellate (s) neurons are seen. Note few glial cells (g). 


\section{Histological results}

Sections in the frontal lobe of control group (Group 1) demonstrated multiple pyramidal neurons with typical main dendrite in the external pyramidal layer of the cerebral cortex. Few stellate neurons with dendrites projecting for short distances in all directions and few granule cells with pale nuclei and minimal cytoplasm were also seen. Few glial cells having elongated darkly stained nuclei were evident in the neuropil (Fig. 1A). In LPS administered group (Alzheimer induced group) (Group 2), some acidophilic masses exhibiting dark nuclei together with multiple deformed neurons, few pyramidal neurons, few granule neurons and multiple glial cells were detected (Fig. 1B). In LPS and TQ administered group (Group 3), acidophilic masses were less numerous and deformed neurons became few. Some pyramidal neurons, few stellate neurons and some glial cells were demonstrated (Fig. 1C). In LPS, PNU-282987 (Alpha7receptor agonist) and PNU-120596 (Alpha7allosteric modulator) administered subgroup (Subgroup 4a) recruited few deformed neurons, multiple pyramidal neurons, few stellate neurons and few glial cells (Fig. 1D). In LPS, TQ and PNU-120596 administered subgroup (Subgroup 4b), few small acidophilic masses with dark nuclei were detected. Few deformed neurons, multi- ple pyramidal neurons, few stellate neurons and few glial cells were also demonstrated (Fig. 1E).

\section{Histochemical results}

Congo red stained sections of group 1 revealed dull staining of neurons and neuropil (Fig. 2A). Group 2 demonstrated some strongly +ve masses (Fig. 2B), while group 3 showed few small +ve masses (Fig. 2C). Subgroup 4a was comparable to control with dull staining (Fig. 2D), while subgroup $4 \mathrm{~b}$ showed accidental small + ve masses (Fig. 2E).

\section{Immunohistochemical results}

P-CREB immunostained sections of group 1 showed multiple + ve nuclei of neurons (Fig. 3A), while in group 2 few + ve nuclei were detected (Fig. 3B). On the other hand, group 3 showed some +ve nuclei (Fig. 3C), subgroups $4 \mathrm{a}$ and $4 \mathrm{~b}$ showed multiple + ve nuclei (Figs. 3D and $3 \mathrm{E})$.

CD44 immunostained sections revealed -ve immunostaining in sections of group 1 (Fig. 4A). Group 2 showed some CD44 + ve spindle cells in the neuropil and within blood vessels (Fig. 4B). Sections of group 3 recruited multiple +ve spindle cells in the neuropil and
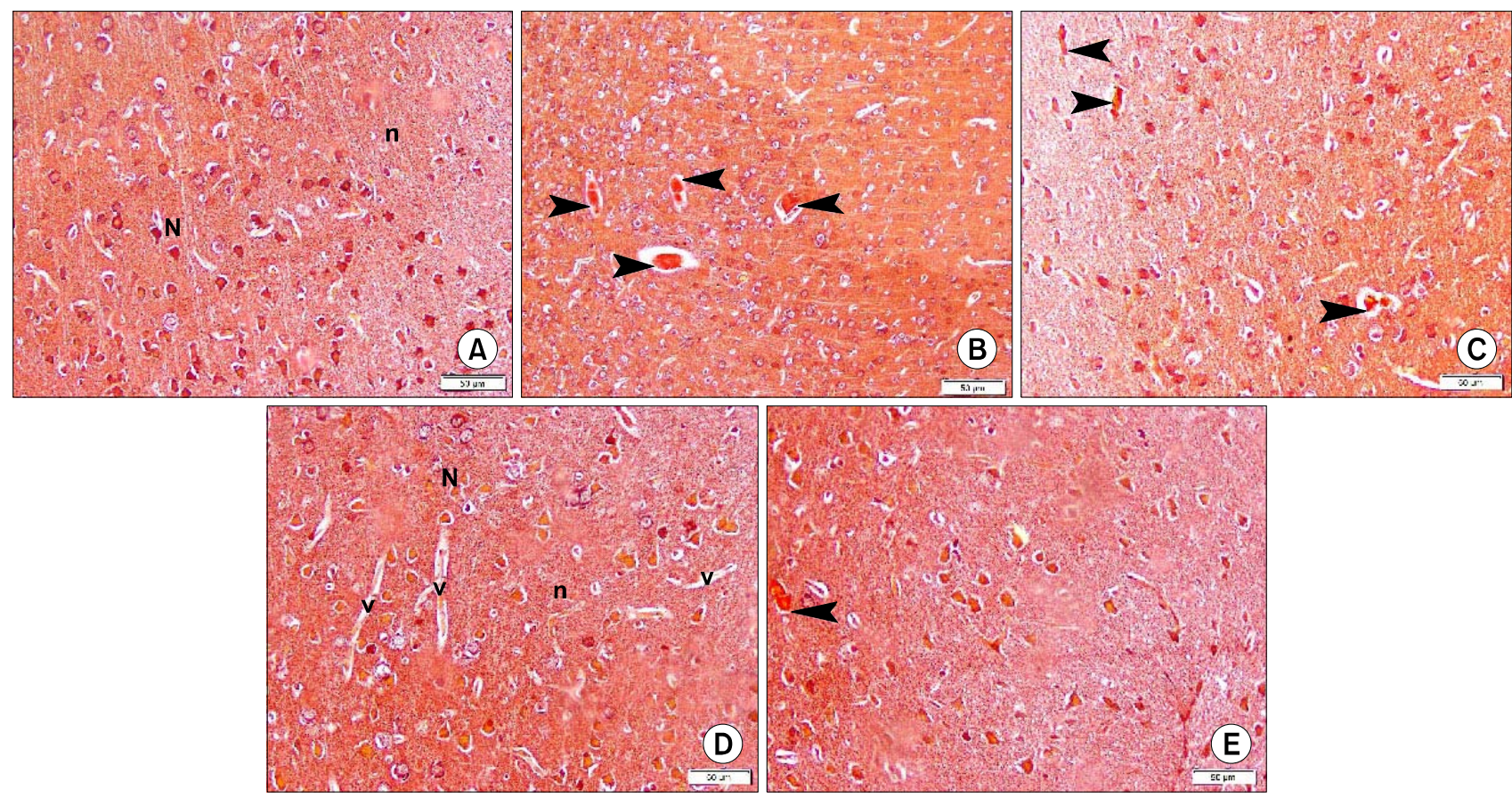

Fig. 2. Photomicrographs of sections in the frontal area of cerebral cortex (EPL) (CR x200). (A) of a rat in group 1 showing dull Congo red (CR) staining of neurons $(\mathrm{N})$ and neuropil (n). (B) of a rat in group 2 showing $4 \mathrm{CR}+$ ve masses (arrowheads). (C) of a rat in group 3 showing 3 small CR + ve masses (arrowheads). (D) of a rat in subgroup 4a showing dull Congo red (CR) staining of neurons (N) and neuropil (n). Note multiple blood vessels (v). (E) of a rat in subgroup 4b showing a small CR+ve mass (arrowhead) (CR x200). 

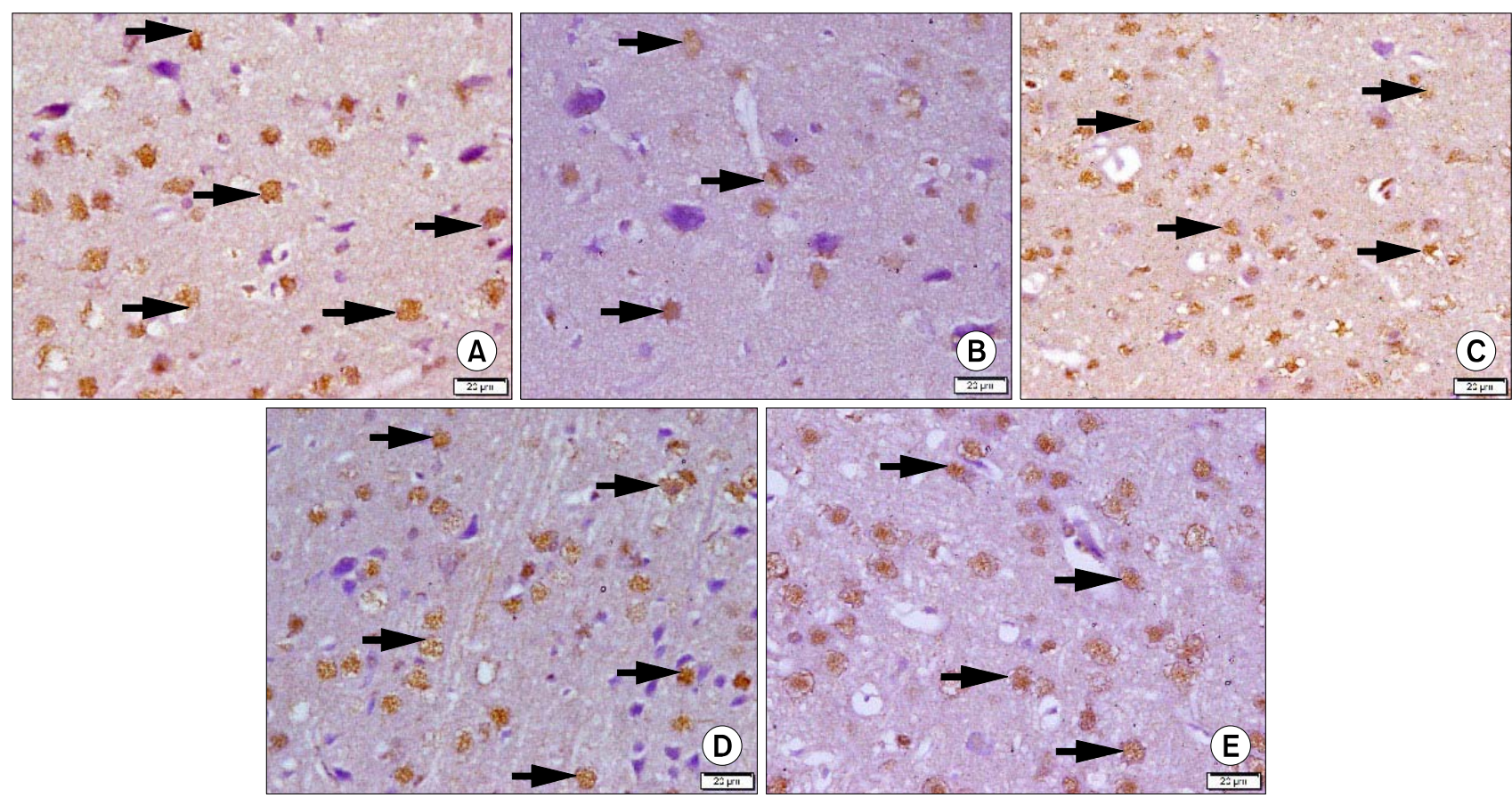

Fig. 3. Photomicrographs of sections in the frontal area of cerebral cortex (EPL) (P-CREB immuno-staining, $x 400$ ). (A) of a rat in group 1 showing multiple + ve nuclei of neurons (arrows). (B) of a rat in group 2 showing few + ve nuclei of neurons (arrows). (C) of a rat in group 3 showing some + ve nuclei of neurons (arrows). (D) of a rat in subgroup 4a showing multiple + ve nuclei of neurons (arrows). (E) of a rat in subgroup $4 \mathrm{~b}$ showing multiple +ve nuclei of neurons (arrows).

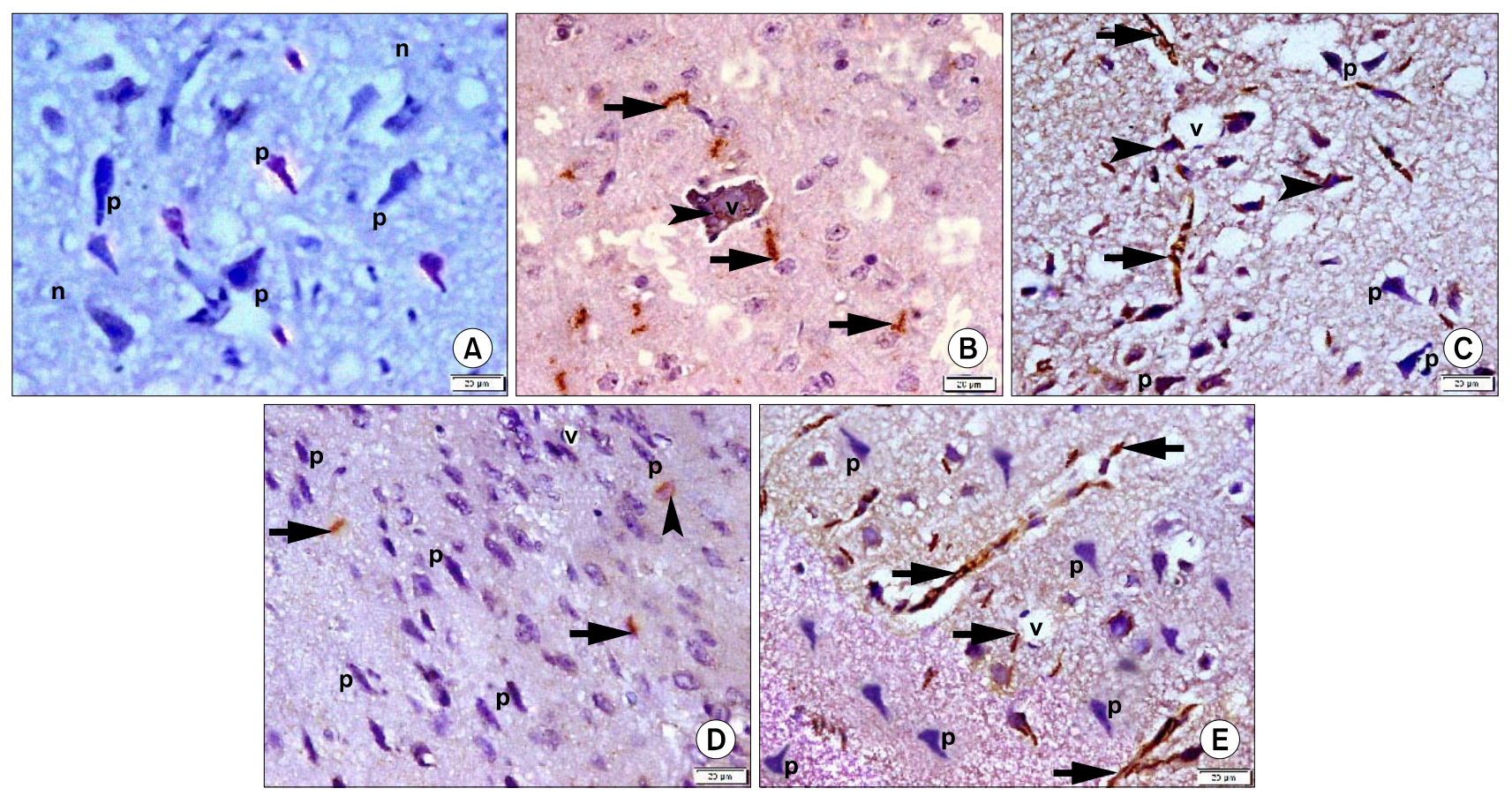

Fig. 4. Photomicrographs of sections in the frontal area of cerebral cortex (EPL) (CD44 immuno-staining, $x 400$ ). (A) of a rat in group 1 showing -ve immunostaining of pyramidal neurons (p) and neuropil (n). (B) of a rat in group 2 showing some +ve spindle cells around (arrows) and inside (arrowhead) a blood vessel (v). (C) of a rat in group 3 showing multiple + ve cells in neuropil (arrows) and fused with neurons (arrowheads). Note some pyramidal neurons (p). (D) of a rat in subgroup 4a showing few + ve cells in neuropil (arrows) and fused with a neuron (arrowhead). Note multiple pyramidal neurons (p) and a vessel (v). (E) of a rat in subgroup 4b showing multiple + ve cells in neuropil (arrows) and multiple pyramidal neurons (p). 
Table 1. Area of deformed neurons, area of glial cells, area of plaques, area \% of P-CREB and area \% of CD44 immunoexpression in control and experimental groups $\pm \mathrm{SD}$

\begin{tabular}{cccccc}
\hline Group & $\begin{array}{c}\text { Area of deformed } \\
\text { neurons }\end{array}$ & Area of glial cells & Area of plaques & $\begin{array}{c}\text { Area \% of } \\
+ \text { ve P-CREB }\end{array}$ & $\begin{array}{c}\text { Area \% of } \\
+ \text { ve CD44 }\end{array}$ \\
\hline Group 1 & - & $0.76 \pm 0.09$ & - & $25.01 \pm 6.52$ & - \\
Group 2 & $7.54 \pm 1.72$ & $3.81 \pm 0.51^{\#}$ & $733.16 \pm 31.23$ & $8.07 \pm 1.62^{\$}$ & $2.98 \pm 0.53$ \\
Group 3 & $3.31 \pm 0.49^{*}$ & $0.94 \pm 0.12$ & $148.44 \pm 18.01$ & $17.39 \pm 4.08$ & $6.44 \pm 0.92^{\circledR}$ \\
Subgroup 4a & $1.98 \pm 0.12^{* *}$ & $0.74 \pm 0.05$ & - & $26.08 \pm 3.22$ & $1.67 \pm 0.21$ \\
Subgroup 4b & $1.81 \pm 0.05^{* *}$ & $0.80 \pm 0.20$ & $68.74 \pm 5.94^{\wedge}$ & $20.75 \pm 4.22$ & $7.36 \pm 1.05^{\circledR}$ \\
\hline
\end{tabular}

*significant decrease compared to Group 2.

**significant decrease compared to Groups 2 and 3.

\#significant increase compared to other groups.

significant decrease compared to Group 2.

significant decrease compared to Groups 2 and 3.

$\$$ significant decrease compared to other groups.

${ }^{\circledR}$ significant increase compared to group 2 and subgroup 4 a.

fused with deformed neurons (Fig. 4C). Subgroup 4a showed few + ve spindle cells in the neuropil and fused with accidental deformed neurons (Fig. 4D). In subgroup $4 \mathrm{~b}$ multiple + ve spindle cells were detected in the neuropil (Fig. 4E).

\section{Morphometric results}

Table 1: Area of deformed neurons, area of glial cells, area of plaques, area $\%$ of P-CREB and area \% of CD44 immunoexpression in control and experimental groups \pm SD.

\section{Discussion}

Despite decades of laboratory and clinical research, $\mathrm{AD}$ is still the leading cause of dementia with poor therapeutic effects of the current treatments (14). This necessitates the exploration of new therapeutic strategies. Thus, the current work was carried out to investigate the combined treatment in LPS-induced AD at histological level.

In the present work, frontal lobe was selected as it was reported to play a crucial role in cognition which is known to be affected in AD (15). The current work used lipopolysaccharide (LPS) to induce AD. There are several models of $\mathrm{AD}$ based on neuroinflammation which is considered the key component in the neurodegenerative process of $\mathrm{AD}$. LPS-induced neuro-inflammation represents the current standard paradigm to study neuro-inflammation both in vivo and in vitro (16).

Group 2 revealed acidophilic masses exhibiting dark nuclei, multiple deformed neurons, few pyramidal neurons with multiple glial cells. These findings are supported by significant increase in area of deformed neurons and that of glial cells in comparison to other groups. The observations are indicative of apoptosis and neuronal degeneration. The degenerating neurons are referred to as red dead neurons with eosinophilic cytoplasm and small shrunken nuclei. The acidophilic masses with dark nuclei might represent apoptotic neuronal cells that fuse together and form masses. Pyramidal neurons in EP layer are the principal neurons that mediate many cognitive functions and they appear to be the main substrate for neurodegenerative changes in AD (12). Glial cells increase secondary to the inflammatory process and as an attempt for clearing the degenerated neurons, supported by Nazem et al. (16).

The current study used CR stain to demonstrate amyloid $\mathrm{A} \beta$ plaques. It was confirmed that $\mathrm{CR}$ is used for identification of beta sheet nature of amyloid plaques (17). Group 2 demonstrated the presence of some CR positive plaques that were absent in subgroup $4 \mathrm{a}$ and became fewer in group 3 and subgroup 4b. Increase in the mean area of plaques was found in group 2. In accordance, $\mathrm{A} \beta$ aggregation has been identified as one of the major causes of neurodegenerative processes in $\mathrm{AD}(18)$ and were demonstrated in cerebral sections of AD induced in mice (19).

Phospho-CREB immunostaining was carried out in the current work. P-CREB is a constitutively expressed nuclear factor (20). It was added that P-CREB signaling is essential for learning and memory (21). On the other hand, group 2 revealed few +ve nuclei of neurons, proved by a significant decrease in the area $\%$ of P-CREB immunostaining. This might be explained on the basis of LPS induced neuroinflammation and accompanied oxidative stress followed by neuron degeneration. Hand in hand, it was reported that oxidative stress induced down 
regulation of P-CREB in cultured rat neurons. Moreover, inverse correlation between $\mathrm{A} \beta$ and P-CREB protein levels was proved (20). The decreased CREB immunostaining in the current model of $\mathrm{AD}$ prove and reinforce the histological findings of $\mathrm{H} \& \mathrm{E}$ stained sections indicative of apoptosis.

In the present work, group 2 demonstrated some CD44 + ve spindle cells in neuropil and in blood vessels. This could be explained as an attempt of MSC for healing of neurodegeneration, being attracted by inflammatory mediators and products of damaged tissue. The inflammatory mediators and the changes in the microenviroment in $\mathrm{AD}$ result in mobilization and differentiation of MSC that can be tissue residents or recruited from the bone marrow (12).

The current work investigated the possible role of Thymoquinone in an animal model of $\mathrm{AD}$. The acidophilic masses, the deformed neurons and the glial cells became few, while the pyramidal cells became more apparent. Few CR + ve masses, some P-CREB +ve nuclei and multiple CD44 +ve cells in neuropil were detected. The previous findings were confirmed by a significant decrease in mean area of deformed neurons and that of plaques with significant increase in mean area of CREB and CD44+ve cells as compared to group 2. The recorded improvement at histopathological level could be attributed to the anti-inflammatory and antioxidant effect of thymoquinone that might interfere with neuro inflammation, $\mathrm{A} \beta$ plaques formation, aggregation and consequently neurodegeneration. It was reported that oxidative stress is a common mechanism contributing to neuronal damage (22). TQ was reported to inhibit $\mathrm{A} \beta$ aggregation in vitro and confer neuroprotection to cultured rat cortical neurons (23). Hand in hand with the current findings, antioxidant and anti-inflammatory activities of $\mathrm{TQ}$ were proved through inhibition of lipid peroxidation and dramatic reduction the of malondialdehyde level in cerebral cortex of rats chronically exposed to toluene (2). In addition, TQ was recorded to reduce apoptosis by reducing activity of caspase-8 and 9 (18).

Subgroups $4 \mathrm{a}$ and $4 \mathrm{~b}$ demonstrated few deformed neurons, $\mathrm{CR}+$ ve masses were absent in subgroup $4 \mathrm{a}$, small and accidental in subgroup $4 \mathrm{~b}$, this was confirmed by a significant decrease in the mean area of both compared to groups 2 and 3. Glial cells mean area was also reduced. On the other hand, mean area of P-CREB + ve nuclei was increased in relation to group 2. The demonstrated findings could suggest the efficiency of combined treatment in $\mathrm{AD}$ model. These findings could be explained on the basis of stimulation of immunologic response by $\alpha 7$
nAChR agonist with reduction of inflammation and consequently neurodegeneration.

Group 4 of the current work was created to evaluate the combined treatment that, to the best of our knowledge, was designed primarily and wasn't tested before. Group 4a demonstrated the combined therapy of PNU-282987 ( $\alpha 7 \mathrm{nAChR}$ agonist) and PNU-120596 ( $\alpha 7 \mathrm{nAChR}$ allosteric modulator) also termed +ve allosteric modulator (PAM). While group $4 \mathrm{~b}$ demonstrated the combined administration of Thymoquinone and PNU-120596 (PAM).

The use of PNU-282987 was based on the knowledge that $\alpha 7 \mathrm{nAChR}$ is expressed in key brain regions, the pre and frontal cortex (24). Moreover, It is expressed on immune cells such as microglia (25) and was significantly reduced in patients of $\mathrm{AD}$ (26). The combination of PNU-120596 (PAM) with either PNU-282987(agonist) or TQ was in consistent with the demonstration that PNU-120596 when combined with donepezil, it increases the drug effective dose range. Moreover, PNU-120596 restored the agonist response of desensitized receptors (3).

Selective $\alpha 7 \mathrm{nAChR}$ agonists demonstrated neuroprotective effects in primary neuronal cultures and rat pheochromocytoma cells PC12. Moreover, PAM affected both potency and efficacy of the agonist (27).

It was demonstrated that $\alpha 7 \mathrm{nAChR}$ binds to $\mathrm{A} \beta$ peptide (24), the interaction between them induces neuron apoptosis and reduction of $\alpha 7 \mathrm{nAChR}$ expression (26). So we could suggest that the agonist and the modulator together interfere with $\alpha 7 \mathrm{nAChR} / \mathrm{A} \beta$ binding thus leaving the receptor free for signaling and hence the desirable effect at histopathological level. This suggestion is supported by the demonstration that the PAM allosteric modulators aimed at unleashing the factors that hinder agonist mediated $\alpha 7 \mathrm{nAChR}$ channel activation (1).

Group 3 and subgroup $4 \mathrm{~b}$ revealed a significant increase in the mean area\% of CD44+ve cells compared to group2 and subgroup 4a, indicating activation of migration of MSCs from the bone marrow to the frontal area of cerebral cortex. The related apparently improved histological picture of group $4 \mathrm{~b}$ in relation to group 3 might be explained via TQ capacity to reduce $\mathrm{A} \beta$ aggregation, as previously mentioned, thus $\alpha 7 \mathrm{nAChR}$ are free for signaling and activity, hence could be targeted by the modulator. Thus, PAM could enhance the neuroprotective effect of Thymoquinone. The activation of migration can be supported by the study conducted by Kim et al. (28), who studied the increase in functional capacity and beneficial effect of bone marrow BM-MSCs on ischemic rat cortical neurons. Activated cell migration and appears to increase their ability to release prosurvival signals and trophic fac- 
tor to rescue ischemic cortical neurons. Mohd-Ali et al. (29) confirmed that activity of BM-MSCs leads to enhanced cell proliferation, migration as well as decrease in growth arrest and apoptosis.

It can be concluded that, at histological level, the early combined treatment in $\mathrm{AD}$ can be more efficient than single drug treatment. TQ or $\alpha 7 \mathrm{nAChR}$ agonist combined with PAM can have an important role in treatment of $\mathrm{AD}$ that is superior to thymoquinone alone. Exceptionally, TQ single or combined with PAM proved activation of MSC. Further investigations are recommended to prove the safety and efficacy of the use of combined treatment at clinical level.

\section{Potential conflict of interest}

The authors have no conflicting financial interest.

\section{References}

1. Vallés AS, Borroni MV, Barrantes FJ. Targeting brain $\alpha 7$ nicotinic acetylcholine receptors in Alzheimer's disease: rationale and current status. CNS Drugs 2014;28:975-987

2. Mehri S, Shahi M, Razavi BM, Hassani FV, Hosseinzadeh H. Neuroprotective effect of thymoquinone in acrylamide-induced neurotoxicity in Wistar rats. Iran J Basic Med Sci 2014;17:1007-1011

3. Callahan PM, Hutchings EJ, Kille NJ, Chapman JM, Terry AV Jr. Positive allosteric modulator of $\alpha 7$ nicotinic-acetylcholine receptors, PNU-120596 augments the effects of donepezil on learning and memory in aged rodents and non-human primates. Neuropharmacology 2013;67:201-212

4. Vicens P, Ribes D, Heredia L, Torrente M, Domingo JL. Effects of an alpha7 nicotinic receptor agonist and stress on spatial memory in an animal model of Alzheimer's disease. Biomed Res Int 2013;2013:952719-952726

5. Gamal El-Din MM, Ahmad ZA, Zekry M, Abdel Wahab $\mathrm{OM}$. Role of estrogen hormone in lipopolysaccharide- induced alzheimer's disease in female rats; possible underlying mechanisms and modulation by progesterone hormone. Medical Journal of Cairo University 2014;82: 175-193

6. Kalappa BI, Sun F, Johnson SR, Jin K, Uteshev VV. A positive allosteric modulator of $\alpha 7 \mathrm{nAChRs}$ augments neuroprotective effects of endogenous nicotinic agonists in cerebral ischaemia. Br J Pharmacol 2013;169:1862-1878

7. Vicens P, Ribes D, Torrente M, Domingo JL. Behavioral effects of PNU-282987, an alpha7 nicotinic receptor agonist, in mice. Behav Brain Res 2011;216:341-348

8. Kumar BP, Kannan MM, Quine DS. Litsea deccanensis ameliorates myocardial infarction in wistar rats: evidence from biochemical and histological studies. J Young Pharm 2011;3:287-296

9. Kiernan JA. Histological and histochemical methods: theo- ry and practice. 3rd ed. London: Arnold; 2001. 111-162

10. Wilcock DM, Gordon MN, Morgan D. Quantification of cerebral amyloid angiopathy and parenchymal amyloid plaques with Congo red histochemical stain. Nat Protoc 2006;1:1591-1595

11. Xu BL, Wang R, Ma LN, Dong W, Zhao ZW, Zhang JS, Wang YL, Zhang X. Comparison of the effects of resveratrol and caloric restriction on learning and memory in juvenile C57BL/6J mice. Iran J Basic Med Sci 2015;18: 1118-1123

12. Bassiony HS, Zickri MB, Metwally HG, Elsherif HA, Alghandour SM, Sakr W. Comparative histological study on the therapeutic effect of green tea and stem cells in Alzheimer's disease complicating experimentally induced diabetes. Int J Stem Cells 2015;8:181-190

13. Emsley R, Dunn G, White IR. Mediation and moderation of treatment effects in randomised controlled trials of complex interventions. Stat Methods Med Res 2010;19:237-270

14. Li X, Bao X, Wang R. Experimental models of Alzheimer's disease for deciphering the pathogenesis and therapeutic screening (Review). Int J Mol Med 2016;37:271-283

15. Girard SD, Baranger K, Gauthier C, Jacquet M, Bernard A, Escoffier G, Marchetti E, Khrestchatisky M, Rivera S, Roman FS. Evidence for early cognitive impairment related to frontal cortex in the 5XFAD mouse model of Alzheimer's disease. J Alzheimers Dis 2013;33:781-796

16. Nazem A, Sankowski R, Bacher M, Al-Abed Y. Rodent models of neuroinflammation for Alzheimer's disease. J Neuroinflammation 2015;12:74-88

17. Castellani RJ, Perry G. The complexities of the pathology-pathogenesis relationship in Alzheimer disease. Biochem Pharmacol 2014;88:671-676

18. Norsharina I, Maznah I , Iqbal S, Lattif LA. Anti- aggregation effects of thymoquinone against Alzheimer's $\beta$ amyloid in vitro. J Med Plants Res 2013;7:2280-2288

19. Khairallah MI, Kassem LA, Yassin NA, El Din MA, Zekri M, Attia M. The hematopoietic growth factor "erythropoietin" enhances the therapeutic effect of mesenchymal stem cells in Alzheimer's disease. Pak J Biol Sci 2014;17:9-21

20. Pugazhenthi S, Wang M, Pham S, Sze CI, Eckman CB. Downregulation of CREB expression in Alzheimer's brain and in $\mathrm{A} \beta$-treated rat hippocampal neurons. Mol Neurodegener 2011;6:60-75

21. Sun L, Jin Y, Dong L, Sui HJ, Sumi R, Jahan R, Hu D, Li Z. Coccomyxa Gloeobotrydiformis Improves Learning and Memory in Intrinsic Aging Rats. Int J Biol Sci 2015;11:825-832

22. Cassano T, Pace L, Bedse G, Lavecchia AM, De Marco F, Gaetani S, Serviddio G. Glutamate and Mitochondria: Two Prominent Players in the Oxidative Stress-Induced Neurodegeneration. Curr Alzheimer Res 2016;13:185-197

23. Alhebshi AH, Gotoh M, Suzuki I. Thymoquinone protects cultured rat primary neurons against amyloid $\beta$-induced neurotoxicity. Biochem Biophys Res Commun 2013; 433:362-367

24. Russo P, Del Bufalo A, Frustaci A, Fini M, Cesario A. 
Beyond acetylcholinesterase inhibitors for treating Alzheimer's disease: $\alpha 7$-nAChR agonists in human clinical trials. Curr Pharm Des 2014;20:6014-6021

25. Stuckenholz V, Bacher M, Balzer-Geldsetzer M, AlvarezFischer D, Oertel WH, Dodel RC, Noelker C. The $\alpha 7$ nAChR agonist PNU-282987 reduces inflammation and MPTP-induced nigral dopaminergic cell loss in mice. J Parkinsons Dis 2013;3:161-172

26. Fan $\mathrm{H}, \mathrm{Gu} \mathrm{R}$, Wei $\mathrm{D}$. The $\alpha 7 \mathrm{nAChR}$ selective agonists as drug candidates for Alzheimer's disease. Adv Exp Med Biol 2015;827:353-365

27. El Kouhen R, Hu M, Anderson DJ, Li J, Gopalakrishnan M. Pharmacology of alpha7 nicotinic acetylcholine receptor mediated extracellular signal-regulated kinase signalling in PC12 cells. Br J Pharmacol 2009;156:638-648

28. Kim YS, Noh MY, Cho KA, Kim H, Kwon MS, Kim KS, Kim J, Koh SH, Kim SH. Hypoxia/ReoxygenationPreconditioned Human Bone Marrow-Derived Mesenchymal Stromal Cells Rescue Ischemic Rat Cortical Neurons by Enhancing Trophic Factor Release. Mol Neurobiol 2015;52:792-803

29. Mohd Ali N, Boo L, Yeap SK, Ky H, Satharasinghe DA, Liew WC, Ong HK, Cheong SK, Kamarul T. Probable impact of age and hypoxia on proliferation and microRNA expression profile of bone marrow-derived human mesenchymal stem cells. PeerJ 2016;4:e1536-1554 